\title{
Schooling Superdiversity: Linguistic features as linguistic resources in two Manenberg classrooms in the Western Cape
}

\author{
Madelynne Madell \\ University of the Western Cape
}

\section{INTRODUCTION}

This study is a working paper which addresses the need for the accommodation of linguistic diversity and mixed linguistic repertoires in the classroom context, due to the rise and changes in migration patterns, as a result of globalization. More specifically, it focuses on linguistic diversity and mixed linguistic repertoires amongst pupils in post- apartheid South African classrooms and investigates how the borrowing of linguistic features by teachers and learners can be used as linguistic resources in the classroom context. By investigating how an informal variety of speech, the borrowing of features across languages, can be utilized as linguistic resource in the classroom context, this paper proposes a move away from formal classroom discourse, to more informal varieties brought to the classroom by learners. Even though scholars such as Woolard (1994) and Ritzau (2014) have highlighted how the ideologies present in institutional settings, perceive the borrowing of linguistic features as an indication of 'less than full linguistic capabilities' (Woolard, 1994:63), various other studies have emphasized the benefits of such language practices in the classroom (see Park, 2013; Blackledge and Creese, 2010b, Canagarajah, 2011). My study will thus also investigate how the language ideologies of the teachers in these two classrooms, affect the occurrence or absence of the borrowing of linguistic features, in this space. The research topic was studied in two grade $r$ classrooms in the area of Manenberg, where classroom observations were used as the main research technique, complimented by interviews and field notes. It can therefore be argued that the study used qualitative research techniques and borrowed research methods from the field of anthropology as some of these methods resemble studies ethnographic in nature. Finally, interactional sociolinguistics was used as the analytical tool.

\section{BACKGROUND}

\section{Superdiversity}

Vertovec (2007), states that over the last few decades, there has been a continuous increase in mobility worldwide, due to the effects of globalization. This 
increase in mobility is characterized by an unbelievable rise in the category of migrants, not only with regards to nationality, ethnicity and language, but also in terms of their reasons for emigrating, routes used during relocation, entry into the labour and housing markets of the host societies and so forth (Vertovec, 2007).Blommaert and Rampton (2011), states that globalization has altered or even changed what we have come to know as social, cultural and linguistic diversity, in societies all over the world. As an umbrella term for the effects of globalization on modern, social life, Vertovec (2007) has coined the term 'superdiversity'. Stroud (2014) states that the goal of superdiversity is to show how mobility has significantly increased across the world, both physically and also on the internet. The diversity in people physically travelling has greatly increased, as these groups now consist of 'refugees (economic, political, sexual), elite migrants (permanent residences, exceptional skills), lowlevel migrants (day workers, border crosser), tourists and so on...' (Stroud, 2014: 399). Furthermore, interactions between diverse groups on cyberspace have significantly increased due to technological inventions, such as social networking (Stroud, 2014: 399).

\section{The borrowing of linguistic features in superdiverse contexts}

As diverse groups now regularly interact in different contexts (home, school, cyberspace and so forth) and coexist in societies across the world, the borrowing of linguistics features across languages has become a common language practice (Stroud, 2014). Jørgensen, Karrebæk, Madsen and Møller, states that linguistic features appear in the form of 'units and regularities' in speech (2011:30). These units include 'words, expressions, sound, even phonetic characteristics such as rounding' (Jørgensen et al., 2011:30). Regularities, on the other hand, refer to the rules with regards to the combining of units into bigger units (Jørgensen et al.,2011). Furthermore, Jørgensen et al. (2011), argues that meaning and values are attached to the combining of units into larger units and that linguistic features are directly linked to values, which are indirectly connected to languages.

Stroud states that the borrowing of linguistic features, in these diverse interconnected settings, occur across languages that speakers do not gain full competence in and that 'belong to other groups of speakers' (2014:399). These interconnected settings, are thus characterized by people with 'mixed linguistic repertoires, genres and languages' (Stroud: 2014:399). Rampton (1995) has coined the term languagecrossing to refer to the borrowing of linguistic features across languages. Language crossing '...involves a sense of movement across quite sharply felt social or ethnic boundaries and it raises issues of legitimacy that participants need to reckon with in the course of their encounter' (Rampton, 1995:291). Other terms, such as 'polylanguaging' (Jørgensen, 2008), 'translanguaging' (Garcia, 2009) but to name a few, are also used to describe the borrowing of features across languages, in these interconnected contexts.

A community where cultural and linguistic diversity is rapidly increasing is the research locality used in this study, Manenberg.

\section{Manenberg}

This community faces various problems such as an unemployment rate of 36.20 percent, housing difficulties and a high 
crime rate (City of Cape Town, 2013). Manenberg has an estimated population of 61615 (City of Cape Town, 2013) and was established in 1966 by the apartheid government for low income 'coloured' families (Willenberg and September, 2008). Post- apartheid, the majority of population in Manenberg remains 'coloured'. However, a comparison between the categories labelled 'ethnic groups' in census of 2001 and 2011, have revealed certain changes in the population found in the area (City of Cape Town, 2001, 2013). Between 2001 and 2011 the percentage of 'coloured' residents in Manenberg decreased, from 94.36 percent to 84.5 percent. The percentage of black African residents in the area increased from 4, 51 percent in 2001 to 10,4 percent in 2011. There was a slight increase in Asian residents in Manenberg, from 0.89 percent in 2001 to 1.5 percent in 2011 . The white population in the community decreased from 0. 24 percent to 0.1 percent between 2001 and 2011. Furthermore, in the 2011 census, a category for 'other' was added to the 'ethnic groups' found in Manenberg. A percentage of $3.5 \%$ was added to this group (City of Cape Town, 2001, 2013). When looking at the above mentioned statistics, it is evident that even though the majority of residents in Manenberg are still 'coloured', diversity in the area is increasing. This is made evident by the increase in 'ethnic groups', such as black African, Asian and the adding of the group 'other' (City of Cape Town, 2001, 2011).

A comparison between Census done in 2001 and 2011, on the languages spoken in Manenberg, revealed the following changes: Afrikaans first language speakers have decreased from 72.07 percent in 2001 to 71.8 percent in 2011. English first language speakers have also decreased from
24.57 percent to 17.8 percent between 2001 and 2011. IsiXhosa first language speakers increased from 2.94 percent in 2001 to 6.8 percent in 2011. Those speaking 'other' languages besides the above mentioned, increased from 0.13 percent to 3.6 percent between 2001 and 2011 (City of Cape Town, 2001). When looking at the above mentioned statistics, one notices a decrease in the dominant language, Afrikaans, and an increase in those speaking IsiXhosa and 'other' languages. It is thus evident that the linguistic diversity in the area has also increased. For this reason, the community of Manenberg can be viewed as an area in Cape Town, South Africa, where superdiversity and its language practices are fast becoming imbedded in the community. Jegels (2011) substantiates this argument by stating that since families speaking different languages have started moving into wards added to Manenberg, such as Tambo Village, children have started borrowing from each other's languages during their linguistic production.

\section{The classroom as superdiverse space}

A context where linguistic diversity is greatly increasing is the classroom. As a result, the effects of migration on linguistic diversity within the classroom context have become a focus of intense interest in the area of linguistic anthropology and sociolinguistics. In studies done on migration and its effects on the classroom, a close look is taken at how the increase and changes in migration patterns have dramatically altered and increased linguistic diversity in classrooms around the world. Scholars such as Creese 2005; Blackledge and Creese 2010a; Li, Juffermans, Kroon and Blommaert, 2011, Kerfoot and Bello- Nonjengela, 2014; and so forth, have done studies of this nature. Studies 
done by scholars such as Blackledge and Creese, (2010b); Canagarajah, (1995, 2011) and Garcia, (2009), have researched how linguistic diversity can be accommodated and also used as linguistic resource through the utilizing of mixed linguistic repertoires in linguistically diverse classrooms.

\section{RESEARCH QUESTIONS}

The aim of this research paper is to study the language practices of two grade $\mathrm{R}$ teachers and their learners in two classrooms in Manenberg, in order to answer the following research questions:

a) To what extend does the medium of instruction in these two classrooms accommodate the linguistic diversity and mixed linguistic repertoires of the learners?

b) Does the language use of the teachers and learners in the classroom context reveal that they are borrowing linguistic features across languages?

c) If the borrowing of features is used by the teachers and learners in the classroom context, how does it function as linguistic resources?

d) How is the borrowing of linguistic features or the absence of this language practice in the classroom influenced by the language ideologies of the teachers?

\section{RESEARCH METHODS AND TECHNIQUES USED TO COLLECT DATA.}

\section{Qualitative Research}

This study took on a qualitative approach, as I mainly relied on classroom observations to collect data.
These observations involved the video recording of the language practices of participants (teachers and learners) as they engaged in the classroom context. The fact that observations were mainly used to gather data, contributed to the authenticity of my data, as this allowed me to observe the spontaneous language use of my participants in the classroom context. Capturing the observations on video camera, allowed me to analyze not only the language use of the teachers and learners but also the non-verbal communication (body language) of the participants. Furthermore, by making use of a video camera, I was able to capture all visual artefacts in the classrooms, which gave deeper insight into the topic being investigated. In addition to video recording my observations; I also made use of field notes to record certain observations made.

Lincoln (1995) argues that qualitative researchers focus on things in their natural setting and attempt to understand and make meaning of daily life occurrences or things that are revealed to them by everyday people. On the other hand, Terre Blanche, Durrheim and Painter (2006) states that qualitative research refers to observing and studying incidents in all of their complexity. Qualitative researchers aim to interpret feelings, experiences, social conditions, or phenomena, as it happens in the real world (Terre Blanche, Durrheim, \& Painter, 2006).

Richards (2003: 9) gives four reasons for using qualitative methodology to collect data:

1. It gets the researcher closer to the practice, to getting a first handsense of what actually goes on in the community;

2. It is above all else a person-centered enterprise;

3. It has transformative potential for 
researcher; and

4. Analysis is based on a wide range of features.

In addition to the use of observations and the making of field notes to gather data, I conducted non-scheduled structured interviews with the teachers. The purpose of the interviews was to assemble information that was difficult to gather during my observations and also to clarify and substantiate certain observations made. These interviews were audio recorded. Terre Blanche, Durrheim and Painter (2006) argue that a non-scheduled structured interview is structured in the sense that the researcher makes a list of the issues to be investigated before the interview. The interviewer has a list of precise questions, but depending on the answers from the participant, the interviewer can use alternative or sub-questions. These interviews were audio recorded. Nonscheduled structured interviews were ideal for my interviews with the teachers as having prepared questions ensured that the most important questions were asked. However, because the interviews were non-scheduled, I was able to ask additional questions that came to mind during the interviews.

\section{Ethnographic Research?}

The collecting of my data was done over the duration of three months. During these three months of fieldwork, I went to the community of Manenberg thrice a week. The first week of being in the field was used to familiarize myself with the area of Manenberg, as the two schools used in my research are situated in this area.

This was done by interacting with community members and visiting public community spaces, such as the community library. By familiarizing myself with the community, I gained insight into the diversification in the area (cultural and linguistic) and the social and economic conditions in which the residents of Manenberg live. To document these findings, field notes were used together with a digital camera to capture images of the area. In the second week in the field, I went to the two grade $r$ classes to familiarize myself with the learning space of my participants and to establish good relationships with the teachers and pupils. Furthermore, this week was used to conduct interviews with the teachers about the language background of the pupils and teachers. Thereafter, my classroom observations commenced. In the final week of data collection, I once again interviewed both grade $r$ teachers in order to clarify and substantiate certain observations made.

As my research involved regularly going to the community of Manenberg for three months, to do observations in the area and most importantly classroom observations in the learning space of my participants, one could argue that my research methods resemble anthropological fieldwork which is regarded as ethnographic in nature. Cameron (2001) states that the term ethnography belongs to the field of anthropology and involves the researching of culture(s) through the use of participant observations.

Anthropologists using ethnographic research methods make use of 'observable techniques' (such as the recording of natural interactions and interviewing of participants), and partake as much as possible in activities happening within the community being studied (Cameron, 2001: 53). The goal of such researchers is to gain insight into how particular communities or cultures function (Cameron, 2001). This is 
done by the researcher immersing him/ herself into the community/ culture's day to day activities but still remaining an 'outsider' in order to act as observer (Cameron, 2001: 53). Blackledge and Creese (2010a) adds to this discussion by stating that ethnographers aim to mirror the social context of their research participants as they interact in social interactions, through representation and interpretation.

Participant observation is not only a research method used in the field of anthropology, but also by those researchers working in fields such as sociolinguistics and cultural studies (Cameron, 2001). However, there are various on-going debates about whether the use of participant observation by researchers in other fields can be labelled ethnography (Cameron, 2001).

This is due to the fact that unlike anthropologists, researchers in other fields do not immerse themselves within the worlds of their participants by living with them and do not spend extensive periods researching their participants and their surroundings (Cameron, 2001). One could argue that the term ethnography have been used extensively in social sciences and it is apparent that what is sometimes regarded as ethnographic research does not meet the standards of 'classical anthropology' (2001: 54). On the other hand, there are often very apparent 'family resemblances' between ethnographic studies done in the field of anthropology and studies in other fields which make use of participant observation (Cameron, 2001: 54). These resemblances include doing research in naturalistic settings, continuous and regular contact with participants, a certain degree of participation by the researcher in the culture/community being investigated and most importantly, the aim of the researcher to gain a group membership level of understanding of the culture/community being studied, instead of seeking 'objective factual data' ( Cameron, 2001:54).

Based on the above discussion, it can therefore be argued that my research methods used for this study, though not ethnographic in an anthropological sense, resembles research methods ethnographic in nature.

\section{Schools used}

Two schools situated in the area of Manenberg were used in this study. In order to protect the identity of these schools, the schools will be referred to as school A and B. For the purpose of this research, the grade $r$ (Foundation Phase) classes at school A and B were used. At school A, the language used as medium of instruction is standard Afrikaans across all grades, including the grade $r$ class used in this study. At school B, the learners receive their education in English or Afrikaans. The senior phase (grade 5-7) at school B, have dual medium of instruction classes. Baker (2007) states that in classes where dual medium of instruction is used, educators teach the subject curriculum in one language one day and then in a different language the following day. In dual medium of instruction classes, the two languages used are very strictly alternated (Baker, 2007). However, grade $\mathrm{r}$ class at school B, which was used in this study, only has English as medium of instruction.

\section{Description of Participants}

The participants used for this study included two grade $r$ (foundation phase) teachers and the grade $r$ pupils in their classes. As the pupils used in the study were in grade $r$, they were be 
between the ages of five- six. The grade $r$ class at school A consisted of thirty one pupils during the time the research was conducted. Twenty six of the pupils in this class were Afrikaans first language speakers, with English as additional language, two English first language speakers, with Afrikaans as additional language, two isiXhosa first language speakers and one French first language speaker. Those pupils with first languages other than the medium of instruction, were thus in the minority. Those learners speaking isiXhosa and French grew up in the cape flats, the majority in the area of Manenberg, and therefore have knowledge of the Afrikaans and English language, even though this knowledge can be viewed as limited. In an interview with the teacher of the grade $r$ class at school B, she stated that 'street slang' or non-standard, informal varieties are brought to the classroom by the pupils.

With regards to the language background of the grade $r$ teacher at School A, it was revealed during that the teacher was born and raised in a community in the cape flats. In both the area and household that she grew up, Afrikaans was used. She received her schooling in Afrikaans, with English as additional language. However, she together with her husband, decided to raise their children with English as home language.

At school B, the grade $r$ class consisted of thirty seven learners during the time the class was used in this study. The majority of the learners in this class are Afrikaans mother tongue speakers, but their parents prefer sending them to an English medium class. There were also five isiXhosa first language speakers in this class. Some of the isiXhosa learners in this class have other African languages or English as a second language, but they also know a bit of Afrikaans, as most of them live in Manenberg or neighbouring communities of Manenberg. Moreover, the English and Afrikaans first language speaking pupils in the class know a bit of isiXhosa as the learners; interact with each other at home or at school.

With regards to the language background of the grade $\mathrm{r}$ teacher at school B, it was discovered that she grew up with Afrikaans as home language, but that she had English as an additional language at school. Furthermore, she pointed out that because some of her childhood friends spoke English, she sees herself as someone who is fairly competent in the English language.

\section{Data Analysis}

Interactional sociolinguistics (IS) was used as the analytical framework for this study. This framework is a branch of discourse analysis that is grounded in the work of Gumperz (1982a, 1982b, and 1999). Interactional sociolinguistics combines and uses various tools as framework for analysis. These tools are borrowed from 'anthropology, linguistics, pragmatics and conversation analysis' (Kerfoot and Bello- Nonjengela, 2014: 4).

According to Gumperz (1999), interactional sociolinguistics (IS) focuses on how meaning is created and interpreted by participants during the communication process. Interactional sociolinguistics places emphasis on communicative practices as the real world site where societal and interactive forces merge (Gumperz, 1999). Gumperz argues that '...the goal is to show how individuals participating in exchanges use talk to achieve their communicative goals in real life situations...' (1999: 453). Rampton (2006), adds to this discussion by stating that interactional sociolinguistics focuses on real life face to faceinteractions where there are significant cultural or power 
differences between the participants involved. Tannen substantiates the above made arguments by stating that interactional sociolinguistics is a form of 'micro analysis' of the language use during real socialinteractions 'in the context of social relationships' (2004:76).

Rampton argues that interactional sociolinguistics 'seeks as rich a data set on interaction as it can get' (2006: 24). Collecting data using interactional sociolinguistics thus comprises of the audio and/or video recording of situated interactions between people and groups, during particular events, which is complimentingby "participantobservation and retrospective commentary from local participants'(Rampton, 2006:24). Studies in interactional sociolinguistics places great emphasis on the semiotic resources used by participants when they are engaged in talk (Kerfoot and BelloNonjengela, 2014:4). These semiotic resources can include intonation, glances, words, code switches and so forth (Kerfoot and Bello- Nonjengela, 2014). Researchers using interactional sociolinguistics thus pay attention to how these semiotic resources are used by participants, in order to achieve their communicative goal (Kerfoot and Bello- Nonjengela, 2014). Ehrlich and Romaniuk (2013) adds to this discussion by stating that another key features of interactional sociolinguistic analysis, which distinguishes it from conversation analysis, is the focus of this framework on the implicit meaning in speech production.

This means that an interactional sociolinguistic approach to discourse goes beyond the analysis of what is openly stated in discourse, by also focusing on implicit meanings signalled by contextualization cues (Ehrlich and Romaniuk, 2013). It can therefore be argued that in addition to analyzing linguistic features present in real life speech production and their part in signalling contextualizing frames, interactional sociolinguistic analysis also includes the investigation of 'the nature of sociocultural context that is potentially signalled by these contextualization cues' (Ehrlich and Romaniuk, 2013: 470). Furthermore, as contextualizing frames are not openly articulated, it is necessary for a researcher using this framework to have additional ways of accessing information about the context in which these features are used (Ehrlich and Romaniuk, 2013).

Once I had collected my interactional data, I started with the transcription of these recordings from oral medium to text medium. As researcher I made the decision to transcribe all of my data, as I wanted to ensure that no important findings that the data might reveal go unnoticed. This decision proved to be advantageous, when during the transcription process patterns were already arising out of the data, which went unnoticed during the time in the field. The patterns were noted down for further investigation once the transcription process was complete. Even though all of my data was transcribed, using all of it proved to be unpractical. For this reason only the most relevant data was selected.

When all the data was transcribed, the variations and linguistic structures in the language use were studied more closely, with the culturally and linguistically diverse backgrounds of the participants in mind. Once instances where the borrowing of linguistic features occurred were identified, my attention shifted to the contextualization cues used during these utterances. By focusing on the contextualization cues used during the utterances, I was able focus on the significance of the context in which the utterances were produced, the meaning attached to it and also the communicative goal of the particular speaker. This finally made it possible for 
me to determine whether the borrowing of linguistic features by the participants function as linguistic resources in the classroom context. Once I had analyzed the data, I once again interviewed the teachers in order to elaborate, contest, or confirm certain observations made.

\section{BIBLIOGRAPHY}

Baker, Colin. 2007. Becoming bilingual through bilingual education. In Auer, Peter and Wei,Li (Eds), Handbook of multilingualism and multilingual communication (pp. 131-155). NewYork: Mouton de Gruyter.

Blackledge, Adrian, and Creese, Angela. 2010a. Multilingualism: A Critical Perspective. New York: Cambridge University Press.

Blackledge, Adrian, and Creese, Angela. 2010b. Translanguaging in the bilingual classroom: pedagogy for learning and teaching? Modern language journal, 94, (pp.103-115).

Blommaert, Jan, and Rampton, Ben. 2011. Language and Superdiversity. In Jan, Blommaert, and Ben Rampton (Eds.),Diversities, 13(2), 1-. RetrievedJune7,2012,from www.mmg. mpg.de/diversities and www.unesco.org/ shs/diversities.

Canagarajah, Suresh, A. 1995. Functions of code switching in the ESL classrooms: Socialising bilingualism in Jaffna. Journal of Multilingual and Multicultural Development, 16, (pp.173-196).

Cameron, Deborah. 2001. Working with Spoken Discourse. London: Sage Publications.

Canagarajah, Suresh. A. 2011. Translanguaging in the Classroom: Emerging issues for research and pedagogy. Applied Linguistics Review, 2(pp.1-28). Retrieved January, 9 2012, doi:10.1515/97831 10239331.

City of Cape Town, 2001.City of Cape Town2001 Census Suburb Manenberg. City of Cape Town.
Creese, Angela. 2005. Teacher Collaboration and Talk in Multilingual Classrooms. Clevedon: Multilingual Matters.

City of Cape Town. 2012. City of Cape Town - 2011 Census.City of Cape Town.

City of Cape Town, 2013.City of Cape Town2011 Census Suburb Manenberg. City of Cape Town.

Ehrlich, Susan, and Tanya, Romanuik. 2013. Discourse Analysis. In Robert, J, Podesva, and Devyani, Sharma. (Eds). Research Methods in Linguistics. New York: Cambridge University Press, (pp.460-493).

Gumperz, John, J. 1982a. Discourse Strategies. Cambridge University Press.

Gumperz, John, J. (Ed.). 1982b. Language and Social Identity. Cambridge University Press.

Gumperz, John, J. 1999. On interactional sociolinguistic method. In Sarangi, Srikant\& Roberts, Celia. (Eds), Talk, Work and Institutional Order: Discourse in Medical, Mediation and Management Settings. New York: Mouton de Gruyter, (pp.453-471).

García, Ofelia. 2009. Bilingual Education in the 21st Century: A Global Perspective. Oxford: Wiley Blackwell.

Jegels, Dmitri, G.A.2011. The literacy orientation of preschool children in a multilingual environment : The case of post -apartheid Manenberg. Unpublished Masters Thesis. University of the Western Cape.

Jørgensen, Jenn.N. 2008. Polilingual Languaging Around and Among Children and Adolescents. International Journal of Multilingualism, 5(3)(pp.161176). DOI: $10.1080 / 14790710802387562$

Jørgensen, Jens. N, Martha, S Karrebæk, Lian, M, Madsen, and Janus, S, Møller. 2011. Polylanguaging in Superdiversity. In Jan, Blommaert, and Ben, Rampton (Eds), Diversities, 13(2) (pp. 1-21).

Retrieved June 7, 2012, from ww.mmg. mpg.de/diversities and www.unesco.org/ shs/diversities

Kerfoot, Caroline, and Basirat, O, BelloNonjengele. 2014. Game Changers? Multilingual learners in a Cape Town 
primary school.Tilburg Papers in Culture Studies, 97.

Li,Jinling, Kasper Jufferman, Sjaak, K Kroon, and Jan Blommaert. 2011. Chineseness as a moving target Intermediate report for the HERA Project, Tilburg Case Study.Tilburg Papers in Culture Studies, 19.

Park, Mi Sun. 2013.Code-switching and Translanguaging: Potential Functions in Multilingual Classrooms. Columbia University Working Papers in TESOL E Applied Linguistics, 13(2), (pp. 50-52).

Rampton, Ben. 1995. Crossing: language and ethnicity among adolescents. London: Longman.

Richards, Keith. 2003. Qualitative Inquiry in TESOL. New York: Palgrave Macmillan.

Rampton, Ben. 2006. Crossing: Language and ethnicity among adolescents. 2nd ed. Manchester: St. Jerome.

Ritzau, Ursula. 2014. Learner language and polylanguaging:how language students' ideologies relate to their written language use. International Journal of Bilingual. Retrieved, September, 18, 2014, doi: $10.1080 / 13670050.2014 .936822$

Stroud, Christopher. 2014. Linguistic diversity and its discontents. In Zannie,
Bock and Gift, Mheta (Eds), Language, Society and Communication (pp. 393-403). Pretoria: Van Schaik.

Tannen, Deborah. 2004. Interactional Sociolinguistics. In Ulrich Ammon, Norbert, Dittmar, Klaus, J, Matteheier, Peter, Trudgill (Eds), Sociolinguistics: An International Handbook of the Science of Language and Society. Berlin and New York: Walter de Gruyter, (pp78-88).

Terre Blanche, Martin, Kevin, Durrheim, and Desmond Painter. 2006. Research in Practice: Applied methods for the social sciences, 2nd Edition. Cape Town: UCT Press. (pp.1024- 1054).

Retrieved, June, 20, 2010, doi: 10.1080/01419870701599465

Vertovec, S. (2007). Superdiversity and its implications. Ethnic and Racial Studies, 30(6), (pp.1024- 1054). Retrieved, June, 20, 2010, doi: 10.1080/01419870701599465

Woolard, Kathryn, A. 1994. "Language Ideology: Issues and Approaches". Pragmatics 2: (pp.235-249).

Willenberg, Ingrid, A, and Roseline, September. 2008. Profile of the Manenberg community. Unpublished report, University of the Western Cape, Bellville, South Africa. 